\title{
A European perspective of the cost effectiveness of facial composite tissue allotransplantation
}

\author{
Tiffanie-Marie Borg $^{1} \cdot$ Seema Yalamanchili ${ }^{2} \cdot$ Shadi Ghali $^{3} \cdot$ Simon Myers $^{1} \cdot$ Simon Holmes $^{1} \cdot$ Ali Ghanem $^{4}$ (D)
}

Received: 22 July 2019 / Accepted: 5 November 2019 / Published online: 25 November 2019

(C) The Author(s) 2019

\begin{abstract}
Background Facial composite tissue allotransplantation (CTA) may be considered in cases of severe facial injury. To date, no reports have analysed the cost of potential facial CTA in the UK. The aims of this study were to establish (1) the cost implications without facial CTA, necessitating multiple reconstructive procedures in cases with severe facial deformities, and (2) if facial CTA would be cost-effective in the UK given recent European and North American published cost analyses.

Methods Hospital episodes' data from two potential candidates for facial CTA were used to calculate cost of treatment. In these cases, severe facial trauma was managed by multiple disciplinary teams performing numerous conventional reconstructive procedures. One case served as an indicator of the cost of primary reconstruction during the immediate post-traumatic episode, from admission until first discharge. The other served as an indicator of the accumulative cost of care following primary reconstruction from first discharge to six years later. Costs incurred served as a guide for the cost of standard reconstruction in the UK. These were compared with the costs of similar reconstructive procedures performed in the USA. This was used with data reporting the cost of facial CTA in the USA and France to predict the cost of facial CTA in the UK.

Results Analysis revealed a cost benefit for facial CTA in a UK context that would become apparent from the third year posttransplant onwards.

Conclusion Facial CTA may therefore be a more cost-effective long-term reconstructive option for patients with severe facial defects.

Level of evidence: Level V, risk/prognostic study.

Keywords Reconstruction · Face transplantation · Vascularised composite tissue allotransplantation $\cdot$ Cost-effectiveness analysis . Health cost containment
\end{abstract}

\section{Introduction}

The first partial facial composite tissue allotransplantation (CTA), performed in November 2005 [1], marked a breakthrough in medical history and caused a stir with both the

Tiffanie-Marie Borg

t.borg@smd14.qmul.ac.uk

Seema Yalamanchili

seema.yalamanchili@nhs.net

Shadi Ghali

shadi.ghali@nhs.net

Simon Myers

simon.myers@qmul.ac.uk

Simon Holmes

s.holmes@qmul.ac.uk medical community and the general public. Since then, issues regarding surgical, post-operative, immunological and psychological risks, and the ethics of the procedure have been an intense source of debate $[2,3]$. With increasing numbers of patients undergoing facial CTA, the procedure is now
Ali Ghanem

a.ghanem@qmul.ac.uk

1 Queen Mary University of London, London, UK

2 St Mary's Hospital, Paddington, London, UK

3 The Royal Free Hospital, Hampstead, London, UK

4 Academic Plastic Surgery, Blizard Institute, Barts and the London School of Medicine and Dentistry, Queen Mary University of London, 4 Newark Street, London E1 2AT, UK 
gaining wider acceptance as a viable reconstructive option in those with extensive facial injury and tissue loss [4]. The fortieth facial CTA was performed at the Cleveland Clinic (Ohio) in May 2017, transforming the life of 21-year-old Katie Stubblefield who, following an attempted suicide by a gunshot blast injury to the face in 2014, lost much of the structure of her face as well as the ability to chew, swallow, and breathe unaided [5]. Indications for facial CTA included severe panfacial defects resulting from burns, trauma, animal bites, or ballistic injury [6]. In the UK, successful CTA is so far limited to the hands and solid organs. These have demonstrated cost effectiveness but, to date, there have been no reports comparing the costs of potential facial CTA in the UK with conventional facial reconstruction. For facial CTA to be implemented in the current UK National Health Service setting, it would be important to understand the expenses and potential benefits of the procedure as an alternative to conventional reconstructive techniques. Therefore, the purpose of this short communication is to pragmatically estimate the potential cost benefit of facial CTA in the UK, based on known UK costs and analysis of the US and French experiences.

\section{Our analysis: methodology}

Two patients with severe facial injuries who would have been potential candidates for facial CTA were used in this analysis. Both were managed by a multidisciplinary team composed of plastic surgeons, maxillofacial surgeons, ENT specialists, ophthalmologists, radiologists, specialist nurses, physiotherapists, occupational therapists, and a speech and language therapy (SaLT) team.

Candidate one served as an indicator of the costs of primary reconstruction. He was a 31-year-old man who suffered a selfinflicted gun shot to the face, resulting in a significant panfacial defect, right globe rupture (non-salvageable), left lens dislocation, a comminuted mandibular and hard palate fracture with bone loss, and degloving of the soft tissue of the face. Primary reconstruction necessitated numerous procedures: enucleation of one eye, tracheostomy, wound debridement, open reduction internal fixation (ORIF) of the mid-face and mandible fractures, suturing of facial lacerations and change of facial packs. Bone and soft tissue reconstruction was then carried out using a scapular and latissimus dorsi free flap reconstruction of the palate, lower lip and mandibular defects. He had numerous revisions and local flap reconstruction procedures until his discharge from this acute episode. Candidate two served as an indicator of the accumulative cost of care following primary reconstruction by conventional procedures. He was a thirty-seven-year-old male who was injured by self-immolation in a political protest, resulting in severe full thickness burn injuries to the face and hands, as well as bilateral compartment syndrome of the lower extremities. Following the primary reconstruction with acellular dermal matrix and skin grafting, he required seventeen secondary facial procedures to address various scarring and wound healing complications along with a total of 346 days of inpatient stay and 100 outpatient appointments and associated investigations. The cost of primary and secondary care of these two cases was calculated according to the local UK NHS Trust tariff. These costs were compared with the cost analyses performed in the USA and France to enable an extrapolation of data and, ultimately, prediction of the cost for a facial CTA procedure in the UK.

\section{Cost analyses of facial CTA in the USA}

Cost analysis comparing facial CTA with conventional reconstruction in the USA, including inpatient costs (surgical, nursing, anaesthesia, pharmacy, and pathology) and outpatient costs (physician and medication costs), were performed by Siemionow M et al. (2011) [7]. This analysis was based on the first facial CTA performed in the USA, a case involving a shotgun blast injury victim whose face had previously been managed with multiple conventional reconstructions but which had resulted in suboptimal outcome [8]. These various reconstructive procedures cumulatively amounted to $\$ 206,646$ while, the direct cost of subsequent facial CTA amounted to $\$ 307,129$ ( $\$ 232,893$ peri-operatively and $\$ 74,236$ post-operatively). This represents a $12.7 \%$ net increase in the cost for CTA, but this patient's case was complicated by the use of a cytomegalovirus (CMV)-positive donor which gave rise to three episodes of $\mathrm{CMV}$ infection requiring hospitalisation - a direct total cost of $\$ 13,884$. Furthermore, this was the first attempt at facial CTA in the USA and one would expect the surgical costs (accounting for the main proportion of total facial CTA expenses - $\$ 97,811$ - or $42 \%$, in this case) to fall with increasing surgical practice and the implementation of specific facial CTA guidelines [9]. A one-year comparative cost analysis in Boston using hospital billing records for conventional reconstruction (2000 to 2010) and facial CTA (2009 to 2011) patients supported this primary analysis, demonstrating that the mean one-year cost of facial CTA $(\$ 337,360)$ is significantly higher than that of conventional reconstruction $(\$ 70,230)$. However, adjustments based on the severity of injury and area of tissue loss resulted in similar cost profiles [10]. Furthermore, following the major expense during the initial month of surgery, a drastic fall in expenses for both surgical options was observed: mean conventional reconstruction costs decreased from $\$ 58,032$ (month 1) to $\$ 1690$ (month 10) while that of facial CTA fell from $\$ 231,879$ (month 1) to $\$ 1722$ (month 10). The cost profiles approached parity from 8 months post-surgery. Given this and the frequent need for revision surgery in patients managed by 
conventional reconstruction, there might be a positive cost benefit ratio of facial CTA.

\section{Cost efficacy of facial CTA in the EU}

Of the forty-one partial and full facial CTA procedures reported to date, twenty-five have been performed in Europe [11]. Cost analyses comparing facial CTA to conventional reconstruction in the EU have not been reported yet. However, cost analysis for preoperative investigations, operative procedures, and hospitalisation in the first five facial CTA patients at Henri Mondor Hospital (France), has enabled comparison with the expenses incurred with solid organ transplantation at the same institution [12]. The mean total cost for a facial CTA was $€ 129,798$ with a range from $€ 102,227$ to $€ 170,071$, depending on procedure length, occurrence of complications, and subsequent duration of ICU stay or general hospitalisation. This was significantly more expensive than solid organ transplantation (heart, liver, kidney), with the closest to the average facial CTA cost being heart transplantation (mean cost of $€ 85,518$ ) followed by liver transplantation (mean cost of $€ 64,247$ ). The cost of solid organ transplantation at Henri Mondor Hospital is comparable to that reported across Europe, including the UK. Interestingly, the cost for facial CTA performed in Europe was found to be consistently lower compared with that reported in the US teams: $\$ 232,893$ [7] (approximately equating to $€ 198,546$ ). This may be partly attributable to health care system differences. However, case variation is also bound to play a significant part as care is tailored to each patient's requirements and will therefore involve different degrees of tissue repair and post-operative management.

\section{Cost efficacy of facial CTA in the UK}

In the UK, solid organ transplantation is the treatment of choice for patients with serious organ pathology, with procedure costs ranging from $£ 34,000$ for a pancreatic islet transplant to $£ 240,500$ for an adult heart transplant [13]. Though expensive and complex, transplantation is undeniably lifetransforming: various analyses reporting cost per QALY (quality adjusted life year) conclude that the benefits from transplantation outweigh the expenses [13-16]. Furthermore, depending on the organ transplanted, there can be a concomitant financial benefit for the procedure. For example, in 2008-2009, kidney transplantation was performed on 2497 patients, with a resultant $£ 50.3 \mathrm{~m}$ annual saving in NHS dialysis expenses, which continues until graft failure [17].

Our primary analysis established the cost implications for life without facial CTA in the UK. The total cost of primary reconstruction for candidate one, including all surgical procedures, 197 days of hospital admission, and necessary investigations, totalled $£ 136,656$. The cost of care incurred after the primary reconstruction by conventional procedures was inferred from the second candidate. He required seventeen secondary procedures with 346 days of inpatient stay and 100 outpatient appointments and associated investigations over a 6 -year period. This amounted to $£ 164,723$, averaging $£ 27,453$ per year. These costs were compared with the findings of Siemenow et al. (2011) [7] whose analysis of care costs for a gunshot victim in the USA yielded a total combined cost of $\$ 353,480$ ( $£ 222,692$ ), including primary conventional reconstruction and follow-up care for three years. This is comparable to the cost of primary reconstruction in the UK: combining costs from the two patients included in this study, the total for primary conventional reconstruction together with three years of post-operative care amounted to $£ 219,015$ (Table 1).

Comparison of the UK and US costs for primary reconstruction gave a cost of care ratio of approximately $1: 1$ ( $£ 219,015$ (UK): $£ 222,692$ (US)). Using this assumed cost ratio, it was possible to predict the cost of facial CTA in the UK. The cost of facial CTA in the USA reported by Siemenow et al. (2011) [7] amounted to $\$ 349,959$ ( $£ 220,474)$. This gives a predictor of facial CTA costs in the UK of $£ 220,474$, or a cost of $£ 210,474$ when the cost of immuno-suppression is deducted ( $£ 5000$ per year for 2 years) (Table 2). Analysis in France [12] did not include the cost of primary reconstruction and follow-up care prior to facial CTA nor it include the cost of follow-up care in the years following the procedures. These could therefore not be directly compared with the UK and US cost analyses. The French study [12] evaluated the cost of five facial CTA procedures performed in France and compared the cost of heart, liver, and kidney transplantation in France with that in the UK. This revealed similar cost profiles for solid organ transplantation between the EU and UK. Assuming that this also applies to the cost of facial CTA, this suggests that the cost of facial CTA in the UK may be lower than the predicted value using Siemenow et al.'s (2011) [7] study. The average cost of facial CTA in the French study totalled $€ 129,798$ (approximately equal to $£ 112,443$ ), excluding long-term care. Assuming a 1:1 ratio between the French and UK cost-oftransplantation, and incorporating the cost of immunotherapy in the UK ( $£ 5000$ per year), a second predicted cost of facial CTA in the UK was obtained. These predicted costs are summarised and compared with UK standard reconstruction costs in Table 2.

The predicted cost of facial CTA using both the North American and European studies demonstrated a cost benefit for facial CTA that becomes apparent from the third year posttransplant onwards (earlier using the predicted cost value derived from the French analysis). This suggests that in the longterm, facial CTA may be a more cost-effective treatment option for those with severe facial injury. 
Table 1 Overview of expenses involved in primary reconstruction (UK study)

\begin{tabular}{ll}
\hline Cause of expense & Cost \\
\hline Total combined cost of primary reconstruction (candidate one) & $£ 136,656$ \\
Surgical procedures $(\times 7)$ & $£ 24,500$ \\
Inpatient stay $(197$ days) & $£ 105,950$ \\
Outpatient clinic appointments $(\times 7)$ & $£ 698$ \\
Investigations & $£ 5508$ \\
6-year post-operative cost $($ candidate two) & $£ 164,723$ \\
Surgical procedures $(\times 17)$ & $£ 39,000$ \\
Inpatient stay (346 days) & $£ 112,450$ \\
Outpatient clinic appointments $(\times 100)$ & $£ 8324$ \\
Investigations & $£ 4949$ \\
Average post-operative care cost per annum (candidate two) & $£ 27,453$ \\
Total cost of primary reconstruction and 3 years of follow-up care & $£ 219,015$ \\
\hline
\end{tabular}

Though our findings suggest that implementing facial CTA would make financial sense within the UK healthcare system, further analysis is needed in view of the various limitations encountered. Calculating costs, even within our own finance department, proved challenging. An additional difficulty is national and international variation in costings, a problem that is further complicated by variations in the exchange rate, purchasing power parity, and healthcare financing systems. Furthermore, the longest recorded follow-up for facial CTA patients is ten years, making calculation of long-term ongoing expenses, including potential expenses as a result of complications of immunotherapy, uncertain. The most expensive complication reported following facial CTA to date is CMV infection, resulting in an additional post-operative expense of $\$ 13,884(£ 11,159)$ [8]. In the event of such complications, it may take longer for a cost benefit to become apparent. Ultimately, data from more post-facial CTA patients worldwide as well as patients treated in the UK (with and without facial CTA) is necessary.

\section{Facial CTA, between the prickly ethics of cost and quality of life}

The benefit of facial CTA extends beyond the financial data presented in this analysis. Reconstruction of severe facial defects using skin grafts, local flaps, and/or free tissue transfers often does not fully restore facial symmetry and function. Skin discoloration and contractures [18] frequently develop postoperatively, resulting in a deformed face that is difficult to correct and a patient who undergoes many additional (expensive) reconstructive attempts with little improvement [19]. Continuing to live with severe facial deformity is associated with social isolation, reduced quality of life, and ultimately, an increased risk of depression, anxiety, and/or posttraumatic stress disorder [20-23]. The advantage of facial CTA is that it restores motor and sensory function as well as provides a more normal facial appearance. This is highlighted by Fischer et al. (2015) [24] who evaluated 29 patients preand post-facial CTA using the Facial Disability Index. Prior to facial CTA, patients were managed using conventional

Table 2 Comparison of the cost of conventional reconstruction with predicted cost of facial CTA in the UK

\begin{tabular}{|c|c|c|c|}
\hline & \multirow{2}{*}{$\begin{array}{l}\text { Conventional reconstruction } \\
\text { (cost derived from UK study) }\end{array}$} & \multicolumn{2}{|l|}{ Facial CTA } \\
\hline & & $\begin{array}{l}\text { Cost derived } \\
\text { from US study }\end{array}$ & $\begin{array}{l}\text { Cost derived } \\
\text { from French study }\end{array}$ \\
\hline Cost of procedure & $£ 136,656$ & $£ 210,474$ & $£ 112,443$ \\
\hline Cumulative cost of care 1 year post-op* & $£ 164,109$ & $£ 210,474$ & $£ 112,443$ \\
\hline Cumulative cost of care 2 years post-op* & $£ 191,562$ & $£ 215,474$ & $£ 117,442$ \\
\hline Cumulative cost of care 3 years post-op* & $£ 219,015$ & $£ 220,474$ & $£ 122,443$ \\
\hline
\end{tabular}

${ }^{\mathrm{O}}$ Predicted based on an assumption of a UK:US:EU cost of care of 1:1:1

* Post-procedure costs included procedures/interventions following the primary conventional reconstruction (£27,455 per annum), or immunosuppression following facial CTA ( $£ 5000$ per annum). The immunosuppressive therapy costs for the first year post-facial CTA are covered as a component of the operative/procedure cost 
reconstructive techniques. Compared with pre-transplant, facial CTA recipients reported improvements in sensation, smell, breathing, eating, speaking, and expressing emotions through facial movements. Long-term follow-up studies by Diaz-Siso et al. (2013) [25] and Khalifian et al. (2014) [26] likewise also report a continuous improvement in functional, aesthetic, and psychological outcomes. Analyses of psychological outcomes following facial CTA report significant improvements in sense of self, body image, and social reintegration with a reduced prevalence of depression and anxiety [27-30]. The significant impact that facial CTA can have on a patient's quality of life therefore presents a strong supporting argument for healthcare professionals and policymakers alike.

Given that facial deformity is unlikely to directly cause death, facial CTA is not recognised as life-saving or life-extending. As a result, the ethical considerations associated with this costly procedure have sparked fierce debate. In modern healthcare, the principles of justice, demanding equity of resource allocation, are as important as the other prescriptive pillars of bioethics: beneficence, maleficence, and respect of patient autonomy. Patient assessment is an important component of justice, since transplanting a face to a patient at high risk of complications or even death would be wasteful and unfair to others eligible for the procedure. The Royal College of Surgeons [31] and National Consultative Committee [32] recommend all potential facial CTA candidates undergo extensive physical, psychiatric, and psychosocial assessment using an Institutional Review Board approved protocol. Careful patient assessment and selection is important in the avoidance of doing harm and ensuring beneficence. It minimises the risks of graft failure while striving for positive mental health, normal self-identification, and social reintegration post-procedure. Following assessment, patients eligible for facial CTA should be fully informed of the benefits and risks associated with the procedure. This includes the risks associated with lifelong immunosuppression.

The concept of converting a "healthy" (albeit severely deformed) patient into an individual requiring lifelong immunosuppression has generated unease amongst some of the medico-ethical commentary. In view of the complications and costs associated with immunosuppressives, alternatives for face transplant recipients are being investigated [33]. However, until such a therapeutic substitute becomes available, ethical critics should also consider the alternative for severely disfigured individuals not managed using facial CTA: multiple reconstructive procedures leading to lifelong limited facial function, unacceptable cosmesis, social isolation and ultimately, a poor quality of life. Solid organ transplantation is already being performed for purposes other than saving or extending life. Though dialysis remains a feasible option for patients with renal failure, kidney transplantation is an increasingly recognised alternative despite the associated immunosuppressive risks. This is because kidney transplantation significantly improves quality of life [34-36] while serving as a cost-effective procedure in the long term [37, 38]. Similarly, though facial CTA is not a life-saving procedure in the classical sense, it is life-transforming. With the four pillars of bioethics in mind, in cases of severe disfigurement where conventional reconstructive options will not provide acceptable outcomes, if the patient is deemed eligible for facial CTA, guidelines are followed, and the patient understands the risks and benefits of facial CTA and wishes to undergo the procedure, a case can be made for the allocation of resources to support these patients through facial CTA.

\section{Conclusion}

Facial CTA is a viable treatment option to conventional reconstruction for patients with severe pan-facial defects, with apparent cost benefit from the third year post-procedure. Irrespective of this benefit, the exceptional structural and functional recovery following facial CTA and the resulting alleviation of psychological and physiological suffering makes a strong case for adoption of the procedure.

\section{Compliance with ethical standards}

Conflict of interest Tiffanie-Marie Borg, Seema Yalamanchili, Shadi Ghali, Simon Myers, Simon Holmes, and Ali Ghanem declare that they have no conflict of interest.

Ethical approval For this retrospective evaluation of cost, ethical approval is not required. However, all procedures performed were in accordance with the ethical standards of the institutional and/or national research committee and with the 1964 Helsinki declaration and its later amendments or comparable ethical standards.

Informed consent For this type of study, formal consent is not required.

Open Access This article is distributed under the terms of the Creative Commons Attribution 4.0 International License (http:// creativecommons.org/licenses/by/4.0/), which permits unrestricted use, distribution, and reproduction in any medium, provided you give appropriate credit to the original author(s) and the source, provide a link to the Creative Commons license, and indicate if changes were made.

\section{References}

1. Devauchelle B, Badet L, Langele B, Morelon E, Testelin S, Michallet M, D'Hauthuille C, Dubernard GM (2006) First human face allograft: early report. Lancet. 368:203-209

2. Hutchison I (2006) Face transplants: is the genie out of the bottle? South Med J 99(4):427-429

3. Siemionow M, Ozturk C (2012) Face transplantation: outcomes, concerns, controversies and future directions. J Craniofacial Surg 23(1):254-259 
4. Smeets R, Rendenbach C, Birkelbach M, Al-Dam A, Grobe A, Hanken H, Heiland M (2014) Face transplantation: on the verge of becoming clinical routine? Biomed Res Int 907272

5. Treat J 2018 Williams RT and Jacobs BT. Building Katie's new face. National Geographic; Available from: https://www. nationalgeographic.com/magazine/2018/09/face-transplant-katiestubblefield-surgery-timeline-interactive/ [Accessed 18 August 2018]

6. Yi C, Guo S (2009) Facial transplantation: lessons so far. Lancet. 374(9685):177-178

7. Siemionow M, Gatherwright J, Djohan R, Papay F (2011) Cost analysis of conventional facial reconstruction procedures followed by face transplantation. Am J Transplant 11:379-385

8. Siemionow M, Papay F, Alam D, Bernard S, Djohan R, Gordon C, Hendrickson M, Lohman R, Eghtesad B, Coffman K, Kodish E, Paradis C, Avery R, Fung J (2009) Near-total human face transplantation for a severely disfigured patient in the USA. Lancet. 374: 203-209

9. Siemionow M, Gordon CR (2010) Institutional review board-based recommendations for medical institutions pursuing protocol approval for facial transplantation. Plast Reconstr Surg 126(4): 1232-1239

10. Nguyen LL, Naunheim MR, Hevelone ND, Diaz-Siso JR, Hogan JP, Bueno EM, Caterson EJ, Pomahac B (2015) Cost analysis of conventional face reconstruction versus face transplantation for large tissue defects. Plast Reconstr Surg 135:260-267

11. Theodorakopoulou E, Meghji S, Pafitanis G, Mason KA (2017) A review of the world's published face transplant cases: ethical perspectives. Scars Burn Heal 3:2059514117694402

12. Ruegg EM, Hivelin M, Hemery F, MacIver C, Menjoar MD, Meningaud JP, Lantieri L (2012) Face transplantation program in France: a cost analysis of five patients. Transplantation. 93(11): $1166-1172$

13. Subgroup of the National Specialist Services Committee, National Services Division (Scotland). Commissioning transplantation to 2020. Final Report. [Accessed 20 July 2018]

14. Longworth L, Young T, Buxton MJ, Ratcliff J, Neuberger J, Burroughs A, Bryan S (2003) Midterm cost-effectiveness of the liver transplantation program of England and Wales for three disease groups. Liver Transpl 9:1295-1307

15. Jarl J, Gerdtham UG (2011) Economic evaluations of organ transplantation. A systematic literature review. Nordic J Health Econ: $61-80$

16. Whiting JF, Kiberd B, Kalo Z, Keown P, Roels L, Kjerulf M (2004) Cost-effectiveness of organ donation: evaluating investment into donor action and other donor initiatives. Am J Transplant 4(4): 569-573

17. NHS Blood and Transplant (2009). Cost-effectiveness of transplantation. Available from: https://nhsbtmediaservices.blob.core. windows.net/organ-donation-assets/pdfs/Organ_Donation_ Registry_Fact_Sheet_7_21337.pdf [Accessed 20 July 2018]

18. Parrett BM, Pomahac B, Orgill DP, Pribaz JJ (2007) The role of free-tissue transfer for head and neck burn reconstruction. Plast Reconstr Surg 120(7):1871-1878

19. Agich GJ, Siemionow M (2005) Until they have faces: the ethics of facial allograft transplantation. J Med Ethics 31(12):707-709

20. Prashanth NT, Raghuveer HP, Kumar D, Shobha ES, Rangan V, Rao TS (2015) Anxiety and depression in facial injuries: a comparative study. J Int Oral Health 7(9):94-100

21. Prashanth NT, Raghuveer HP, Kumar D, Shobha ES, Rangan V, Rao TS (2015) A comparative study of post-traumatic stress disorder, anxiety, depression and change in sexual functioning of patients with facial injuries and patients with extremity injuries. J Contemp Dent Pract 16(11):884-892
22. Vickery LE, Latchford G, Hewison J, Bellew M, Feber T (2003) The impact of head and neck cancer and facial disfigurement on the quality of life of patients and their partners. Head Neck 25(4):289 296

23. Islam S, Ahmed M, Walton GM, Dinan TG, Hoffman GR (2010) The association between depression and anxiety disorders following facial trauma - a comparative study. Injury. 41(1):92-96

24. Fischer S, Kueckelhaus M, Pauzenberger R, Bueno EM, Pomahac B (2015) Functional outcomes of face transplantation. Am J Transplant 15(1):220-233

25. Diaz-Siso JR, Parker M, Bueno EM, Sisk GC, Pribaz JJ, Eriksson E, Annino D, Tullius SG, Pomahac B (2013) Facial allotransplantation: a 3-year follow-up report. J Plast Reconstr Aesthet Surg 66(11): 1458-1463

26. Khalifian S, Brazio PS, Mohan R, Shaffer C, Brandacher G, Barth RN, Rodriguez ED (2014) Facial transplantation: the first 9 years. Lancet. 384(9960):2153-2163

27. Chang G, Pomahac B (2013) Psychosocial changes 6 months after face transplantation. Psychosomatics. 54(4):367-371

28. Coffman KL, Siemionow MZ (2013) Face transplantation: psychological outcomes at three-year follow-up. Psychosomatics. 54(4): 372-378

29. Lemmens GM, Poppe C, Hendrickx H, Roche NA, Peeters PC, Vermeersch HF, Rogiers X, Lierde KV, Blondeel PN (2015) Facial transplantation in a blind patient: psychologic, marital and family outcomes at 15 months follow-up. Psychosomatics. 56(4): 362-370

30. Aycart MA, Kiwanuka H, Krezdorn N, Alhefzi M, Bueno EM, Pomahac B, Oser ML (2017) Quality of life after face transplantation: outcomes, assessment tools and future directions. Plast Reconstr Surg 139(1):194-203

31. Morris PJ, Bradley JA, Doyal L, Earley M, Hagan P, Milling M et al (2004) Facial transplantation: a working party report from the Royal College of Surgeons of England. Transplantation. 77(3):330-338

32. Comite' Consultatif National d'Ethique pour les sciences de la vie et de la sante'. L'allotransplantation de tissu composite (ATC) au niveau de la face (Greffe totale ou partielle d'un visage). Paris: Comite' consultative national d'e'thique pour les sciences de la vie et de la sante'; 2004, Report No.: Opinion 82

33. Keener AB (2016) Saving face: the search for alternatives to lifelong immunosuppression for face transplants. Nat Med 22(5):448 449

34. Kostro JZ, Hellmann A, Kobiela J, Skora I, LichodziejewskaNiemierko M, Debska-Slizien A et al (2016) Quality of life after kidney transplantation: a prospective study. Transplant Proc 48(1): $50-54$

35. Hernandez Sanchez S, Carrero JJ, Garcia Lopez D, Herrero Alonso JA, Menendez Alegre H, Ruiz JR (2016) Fitness and quality of life in kidney transplant recipients: case-control study. Med Clin (Barc) 146(8):335-338

36. Egea-Guerrero JJ, Martin-Villen L, Ruiz de Azua-Lopez Z (2016) Quality of life after kidney transplant. Med Clin (Barc) 147(7):326

37. Cavallo MC, Sepe V, Conte F, Abelli M, Ticozzelli E, Bottazzi A, Geraci PM (2014) Cost-effectiveness of kidney transplantation from DCD in Italy. Transplant Proc 46(10):3289-3296

38. Laupacis A, Keown P, Pus N, Krueger H, Ferguson B, Wong C, Muirhead N (1996) A study of the quality of life and cost-utility of renal transplantation. Kidney Int 50(1):235-242

Publisher's note Springer Nature remains neutral with regard to jurisdictional claims in published maps and institutional affiliations. 